\title{
Interaction entre Rhizophagus irregularis DAOM 197198, exsudats racinaires antifongiques du type hévéine et stress hydrique chez le clone d'hévéa IRCA 331 greffé au clone GT1
}

\author{
Eric-Olivier TIENEBO ${ }^{1 *}$, Kouabenan ABO ${ }^{1}$, Kouakou Théodore KOUADIO ${ }^{1}$, Benson \\ Josué Arnold N'GAH ${ }^{1}$ \\ ${ }^{1}$ Laboratoire de Phytopathologie et de Biologie Végétale, Institut National Polytechnique Félix Houphouët-Boigny, BP 1313 \\ Yamoussonkro, Côte d'Ivoire. \\ *Auteur correspondant: eric.tienebo@inphb.ci; +22507 265947.
}

Mots-clés : Exsudats racinaires antifongiques, stress hydrique, Rhizophagus irregularis DAOM 197198, Hevea brasiliensis, Resistance induite.

Keywords: Hevein-like antifungal root exudates, water stress, Rhizophagus irregularis DAOM 197198, Hevea brasiliensis, Induced resistance.

Publication date 31/10/2019, http://www.m.elewa.org/JAPS

\section{RESUME}

Cette étude avait pour objectifs d'évaluer sous serre l'effet des exsudats racinaires de type hévéine sur la mycorhization de l'hévéa et la résistance induite par Rhizophagus irregularis DAOM 197198 contre le stress hydrique chez le clone d'hévéa IRCA 331 greffé sur le GT1. Dans un dispositif en blocs de Fisher, la colonisation de plants de la variété de tomate UC82B et d'hévéa cultivés dans un même pot ou individuellement a été évaluée 15 jours post incoculation, date à laquelle tous les plants de tomate ont été rétirées avant le test de stress hydrique. Vingt-huit jours après inoculation, les mêmes plants d'hévéa ont ensuite été soumis à 3 niveaux de stress hydrique conférés par une capacité de rétention d'eau du pot maintenue à $5 \%, 50 \%$ ou $100 \%$ durant 14 jours. Il en est résulté que le clone d'hévéa a une très bonne intensité de mycorhization $(>70 \%)$ et une bonne abondance arbusculaire $(>40$ $\%$ ). Ces résultats suggèrent que $R$. irregularis DAOM 197198 possèderait un mécanisme de résistance aux exsudats antifongiques du type hévéine. Par ailleurs, la comparaison des indices de réflectance photochimique sous stress des plants non mycorhizés et ceux mycorhizés démontrent clairement que la mycorhization améliore significativement la résistance des plants au stress hydrique. La mycorhization pourrait donc substantiellement engendrer des économies de coûts d'irrigation et de fertilisation en pépinière. Toutefois, ces résultats doivent être confirmés par des tests au champ.

\section{ABSTRACT}

The study objectives were to investigate the effect of hevein-like root exudates on rubber tree mycorrhization and inoculation effect of Rhizophagus irregularis DAOM 197198 on water stress tolerance of the rubber tree clone IRCA 331 grafted on GT1 rootstock. The colonization rate of tomato UC82B and rubber plants grown in same or individual pot was evaluated in a randomized complete blocks design set up in a glasshouse, 14 days post inoculation. After colonization assessment, all tomato plants were removed before water stress test begin. Twenty-eight days after inoculation, the rubber plants were subjected to 3 
levels of water stress conferred by a pot water holding capacity maintained at $5 \%, 50 \%$ or $100 \%$. We found that the clone has a very good mycorrhization intensity ( $>$ to $70 \%$ ) and a good arbuscular abundance ( $>$ to $40 \%$ ). These results suggest that $R$. irregularis DAOM 197198 has a mechanism of resistance to hevein-like antifungal root exudates. In addition, the comparison of the photochemical reflectance indexes under stress of non-mycorrhized and mycorrhized plants clearly shows that mycorrhization significantly improves the resistance of the plants to water stress. Mycorrhization could therefore substantially reduce irrigation and fertilization costs. However, these results must be confirmed by field tests.

\section{INTRODUCTION}

Les plantes cultivées sont soumises à plusieurs contraintes environnementales qui affectent leur croissance, leur développement, leur productivité et leur répartition géographique (Kang et al., 2009). Le déficit hydrique constitue l'un des stress abiotiques les plus connus (Fotso et al., 2019). Les pressions du stress hydrique déclenchent une pléthore de réponses végétales allant d'une modification de l'expression génétique et du métabolisme cellulaire à des changements morphologiques et anatomiques réduisant la croissance et les rendements (Macedo, 2012). En plus de leurs systèmes protecteurs intrinsèques contre ces contraintes, $90 \%$ des plantes vasculaires terrestres vivent en symbiose avec des champignons mycorhiziens à arbuscules (CMA) (Basu et al., 2018; Fotso et al., 2019). Les CMA peuvent contribuer à réduire la sévérité des divers types de stress (Chitarra et al., 2016; Fotso et al., 2019; Hu et al., 2017; Li et al., 2015; Xu et al., 2019). Dans un contexte d'agriculture durable, la mycorhization contrôlée représente un outil potentiel de management agricole respectueux de l'environnement face aux défis du changement climatique et de la réduction des coûts et des inconvénients de la fertilisation combiné à l'irrigation (Sahraoui, 2013). Toutefois, une interrogation se pose quant à la possibilité de l'établissement de la symbiose dans certaines racines telles que celles de Hevea brasiliensis et Urtica dioica exsudant des substances diffusibles antifongiques du type hévéine (Choon Koo et al., 2002; Noonan et al., 2017; Slavokhotova et al., 2014; Sosa Rodriguez et al., 2013; Van Parijs et al., 1991). Cette question est de toute importance, car les résultats de travaux antérieurs sur différents clones d'hévéa se contredisent. Certains auteurs affirment que les exsudations racinaires de l'hévéa contiennent des substances antifongiques du type hévéine qui in vitro ou en culture en pots retardent considérablement la mycorhization ou conduisent à un faible pourcentage de colonisation $(0-15 \%)$ du clone PB 260 par la souche R. irregularis MUCL 41833 (Sosa Rodriguez et al., 2013). D'autres auteurs ont plutôt observé un bon pourcentage de colonisation au champ $(>60 \%)$ du clone RRIM 600 par des isolats de Glomus et/ou Acaulospora (Basumatary et al., 2014; Herrmann et al., 2016). Ces résultats, en apparence contrastés, semblent être fonction du génotype des clones ou des isolats du micro-symbionte. Cette étude vise à déterminer, d'une part, l'impact de l'exsudation racinaire de l'hévéine sur la mycorhization du porte-greffe du clone IRCA 331 (le GT1) en serre et d'autre part, la contribution de la mycorhization à la tolérance du clone d'hévéa IRCA 331 au stress hydrique en serre. Il s'agissait donc de vérifier la première hypothèse selon laquelle une plante très mycotrophe comme la tomate ne puisse mycorhizer lorsqu'elle est dans le voisinage immédiat (dans le même pot) d'un plant d'hévéa, malgré l'apport de propagules mycorhiziennes viables. Les exsudats inhibiteurs vont donc diffuser rapidement et empêcher ou réduire considérablement la mycorhization des racines de tomate et d'hévéa. Les mêmes plants du clone greffé IRCA 331 après invalidation de la première hypothèse ont été soumis à trois régimes hydriques 28 jours post inoculation. Il s'agissait là de vérifier la seconde hypothèse 
selon laquelle les plants mycorhizés ont surtout un meilleur indice de réflectance photochimique (PRI), un indice résistance au

\section{MATERIEL ET METHODES}

3.1 Matériel biologique : Le matériel biologique était composé de plants de pépinière du clone IRCA 331 greffé sur le clone GT1 et recépés à 6 mois d'âge. Ces plants n'étaient pas encore débourrés. Des semences de la variété de tomate UC82B (Bourget et Sanvoisin, France), préalablement désinfectées, pendant 25 min, dans de l'eau de Javel à $8^{\circ} \mathrm{Cl}$ diluée à $3 \%$, puis prégermées pendant 5 jours, sur du papier buvard stérile à l'obscurité et à $25-30^{\circ} \mathrm{C}$, ont aussi été utilisées. Pour l'inoculation mycorhizienne, la souche Rhirophagus irregularis DAOM 197198 a été utilisée dans une formulation commerciale poudreuse (Premier Tech, Canada) contenant 500 spores.g ${ }^{-1}$.

3.1.1 Substrat de culture : Le substrat de culture utilisé était un sol limono-sableux, préalablement tamisé $(5 \mathrm{~mm})$ et stérilisé à la vapeur $\left(120{ }^{\circ} \mathrm{C}\right.$ pendant $1 \mathrm{~h} /$ jour pendant 3 jours consécutifs) avant emploi. Les caractéristiques chimiques du sol étaient les suivantes : $\mathrm{pH}\left(\mathrm{H}_{2} \mathrm{O}\right) 6,78$, matière organique $3,39 \%$; $\mathrm{N} 0,36 \%$; rapport $\mathrm{C} / \mathrm{N} 6,43$; P total 825 ppm; P disponible 50 ppm ; CEC 29,4 cmol. $\mathrm{kg}^{-1} ; \mathrm{Ca}^{2+}$ 8,26 cmol. $\mathrm{kg}^{-1} ; \mathrm{Mg}^{2+}$ 3,106 cmol.kg ${ }^{-1} ; \mathrm{K}^{+} 0,458 \quad \mathrm{cmol}^{\mathrm{kg}}{ }^{-1} ; \mathrm{Na}^{+} 0,218$ $\mathrm{cmol}^{\mathrm{kg}} \mathrm{kg}^{-1}$. La capacité maximale de rétention d'eau (CR) du sol dans les pots de culture a été déterminée selon la méthode des pesées de (Turner, 2019) . Elle valait $1106 \mathrm{ml}$ d'eau dans des pots de culture de 201.

\subsection{Méthodes}

\subsubsection{Conduites et dispositifs} expérimentaux : Les essais ont été réalisés entre janvier et Mars 2018 dans la serre vitrée du Département Agriculture et Ressources Animales de l'Institut National Polytechnique Felix Houphouet Boigny de Yamoussoukro (6'12'10,8' latitude Nord et 5'14'21,876" longitude Ouest). Caractérisation de l'effet des exsudats racinaires d'hévéine sur la mycorhization de la variété de tomate $\mathrm{UC} 82 \mathrm{~B}$ et du clone IRCA 331 stress hydrique, (Gamon et al., 1997; Garbulsky et al., 2011; Peñuelas et al., 2011, 2013) que les plants non mycorhizés.

Différents traitements ont été réalisés pour l'étude portant sur l'inoculation ou non de $R$. irregularis (Ri) et la présence ou non de plants de tomate dans le même pot que des pieds d'hévéa :HRi : Inoculation de $\mathrm{Ri}$ au substrat ne contenant que des pieds d'hévéa ;

1) ToRi : Inoculation de Ri au substrat ne contenant que des pieds de tomate ;

2) ToHRi (ToHRi T et ToHRi H) : Inoculation de $\mathrm{Ri}$ au substrat contenant à la fois des pieds de tomate et des pieds d'hévéa ;

3) To: Pas inoculation de Ri au substrat ne contenant que des pieds de tomate;

4) Ho: Pas inoculation de Ri au substrat ne contenant que des pieds d'hévéa.

Les effets du traitement ToHRi en vue de la mycorhization de la tomate (ToHRi T) ont donc été comparés à ceux de ToRi (témoin positif). De même, les effets du traitement ToHRi, en vue de la mycorhization de l'hévéa (ToHRi H), ont été comparés à ceux de $\mathbf{H R i}$. Les traitements To et Ho ont servi de témoins négatifs pour différencier, à l'observation microscopique, une racine mycorhizée d'une racine non-mycorhizée. À cet effet, un dispositif expérimental en randomisation totale avec 10 répétitions (soit au total, 30 plants d'hévéa et 30 plants de tomate) a été utilisé en serre. Les inoculations ont débuté 15 jours après le re-empotage des plants d'hévéa et semis de la tomate, le temps que les plants d'hévéa récupèrent des chocs du transport et du re-empotage et également pour le constat du débourrement. Dix (10) g d'inoculum mycorhizien ont été répandus dans la rhizopshère des plantes. Les plants témoins négatifs ont également reçu une portion autoclavée de $10 \mathrm{~g}$ prealablement filtré avec un tamis de maille de $30 \mu \mathrm{m}$ de l'inoculum CMA afin de fournir la même population microbienne exempte de propagules MA. Vingt-quatre (24) heures après inoculation, tous les plants ont été arrosés jusqu'à la capacité 
maximale de rétention d'eau du substrat. Cependant, 21 jours durant, les plants recevaient par intervalle de 2 - 3 jours, $1106 \mathrm{ml}$ d'eau bi-distillée et autocalvée depuis le reempotage excepté le jour de l'inoculation. Durant l'essai, la température de la serre a oscillé entre 20,2 et $33^{\circ} \mathrm{C}$; la durée de l'ensoleillement était de 228,7 h et l'humidité relative a varié entre 45 et $85 \%$. Aucun apport de fumure, aucun traitement de pesticides n'a été nécessaire durant l'essai.

3.2.1.1 Caractérisation de l'effet de la mycorhization sur la tolérance du clone d'hévéa IRCA 331 au stress hydrique : Pour l'étude portant sur l'inoculation (Ri) ou non (NM) de R. irregularis DAOM 197198) et 3 niveaux de stress hydriques très contrastées (non-stress, stress modéré et stress sévère) différents traitements ont été effectués. La méthode utilisée, pour l'application de la contrainte hydrique, est celle décrite par Turner (2019). Cette méthode consiste en des pesées qui permettent quotidiennement d'apporter le volume d'eau nécessaire pour maintenir la CR à $100 \%$ (non-stress), 50\% (stress modéré) et 5\% (stress sévère) pendant 14 jours. Un plan factoriel expérimental avec 12 répétitions (72 plants d'hévéa au total) a été utilisé en serre. Les conditions et autres pratiques de conduite expérimentale étaient identiques à celles indiquées précédemment. Les applications des différents régimes hydriques contrastées et susmentionnés ont commencé 28 jours post inoculation (jpi). Elles ont été étendues sur 14 jours.

3.2.2 Détermination des paramètres d'infectivité : Les mesures de la colonisation racinaire par le CMA sont intervenues 15 jours après inoculation (jpi) selon la méthode décrite par Trouvelot (Guillemin et al., 1992; Trouvelot et al., 1986). Pour ce faire, 30 fragments de racines d'environ $1 \mathrm{~cm}$ de longueur ont été préalablement colorés au bleu de trypan selon le protocole de Phillips \& Hayman (1970), puis disposés parallèlement entre lame et lamelle, à raison de quinze par lame, dans une goutte de glycérol. L'examen histologique des structures mycorhiziennes dans chaque fragment racinaire s'est faite au microscope photonique Amscope avec l'aide de deux barèmes de classe de colonisation et d'abondance (Figure 1) (Trouvelot et al., 1986).

A

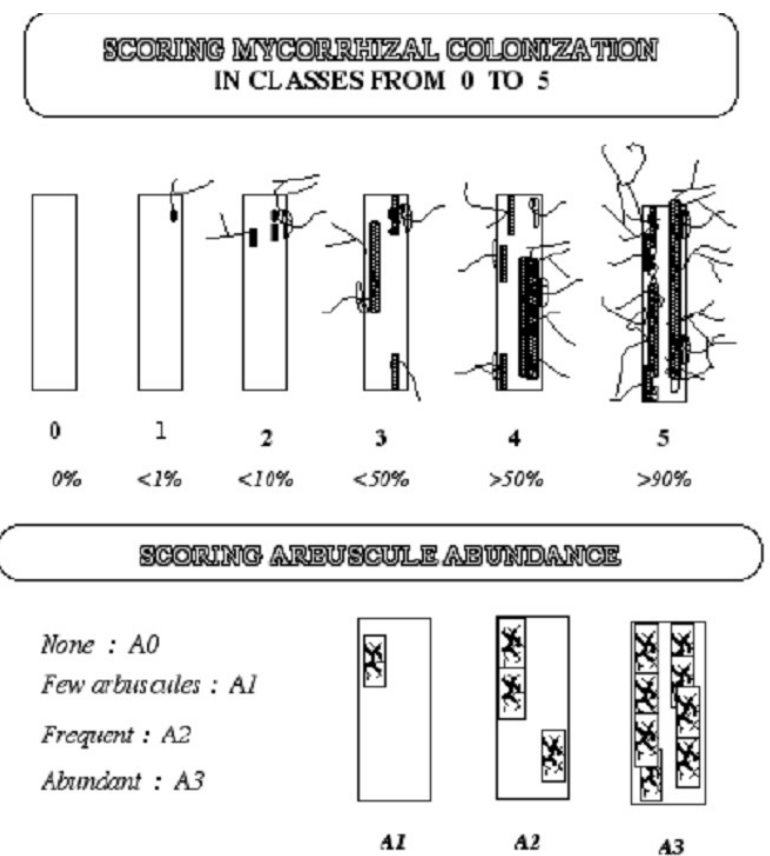

Figure 1. Echelle de notation de l'intensité de mycorhization (A) et de l'abondance arbusculaire (B) (Trouvelot et al., 1986). 
Les paramètres d'infectivité déterminés sont les suivants :

La fréquence de mycorhization du système racinaire $\mathbf{F} \%$, qui est évaluée comme suit :

$\mathrm{F} \%=\frac{\text { nombre de fragments mycorhizés } \times 100}{\mathrm{n}}$, où $\mathrm{n}$

désigne le nombre total de fragments de racines.

L'intensité de mycorhization $\mathbf{M} \%$ du système racinaire est obtenu suivant la formule :

$\mathrm{M} \%=\frac{95 \mathrm{n}_{5}+70 \mathrm{n}_{4}+30 \mathrm{n}_{3}+5 \mathrm{n}_{2}+\mathrm{n}_{1}}{\mathrm{n}}$, où $n_{i}$ désigne le

nombre de racines ayant une classe $\mathrm{i}$ de colonisation (Figure 1A) et n, le nombre total de fragments de racines déposés entre lame et lamelle.

Les paramètres d'effectivité (renseignant sur la fonctionnalité) de la symbiose sont :

L'abondance arbusculaire $\mathbf{a} \%$ des parties mycorhizées des fragments de racines

$\mathrm{a} \%=\frac{100 \mathrm{~mA}_{3}+50 \mathrm{~m} A_{2}+10 \mathrm{~m} A_{1}}{100}$, où $\mathrm{mA}_{3}, \mathrm{~mA}_{2}$, et

$\mathrm{mA}_{1}$ sont les $\boldsymbol{m} \boldsymbol{\%}$, évalués à l'aide des classes de figures d'arbuscules (Figure 1B) notées $A_{3}, A_{2}$, $A_{1}$, respectivement, avec

$\mathrm{m} A_{i}=\left(\frac{95 n_{5} A_{i}+70 n_{4} A_{i}+30 n_{3} A_{i}+5 n_{2} A_{i}+n_{1} A_{i}}{\text { nombre de fragments mycorhizés }}\right) \times \frac{100}{\mathrm{~m}}$

, où $n_{i}$ désigne le nombre de racines ayant une

classe i de colonisation (Figure 1A)

L'abondance arbusculaire $\mathbf{A} \%$ du système racinaire est calculée comme suit : $\mathrm{A} \%=$ $\mathrm{a} \times(\mathrm{M} / 100)$.

\subsubsection{Détermination des paramètres des} physico-chimiques des substrats de culture : A l'aide d'un $\mathrm{pH} /$ moisture tester, le $\mathrm{pH}$ et l'humidité du substrat de culture ont été mesurés tous les deux jours depuis l'imposition de la contrainte hydrique. Ces mesures ont été réalisées à 08:00 AM, 01:00 PM et 05:30 PM.

\subsubsection{Détermination des paramètres} morphométriques et physiologiques des plantes : La longueur et le diamètre à la base de la tige issue du greffon ont été mesurés respectivement au moyen d'un ruban-mètre et d'un calliper électronique en fin d'expérimentation (42 jpi). La température foliaire de la plus jeune feuille complètement développée a été mesurée à l'aide d'un thermomètre à infrarouge (LCD laser IR GM 320) dans les conditions sus-indiquées.. La teneur en chlorophylle également de la plus jeune feuille totalement développée a été déterminée en unités SPAD, en fin d'expérimentation, avec un chlorophyll meter SPAD502 (Minolta Camera, Japan). La mesure de l'indice de réflectance photochimique (PRI) a été effectuée à l'aide du PlantPen PRI 210 (PSI, Photon Systems Instruments, Drasov, Czech Republic) en comparant la réflectance des feuilles dans deux bandes de longueur d'onde étroites centrées à $531 \mathrm{~nm}$ et $570 \mathrm{~nm}$. Ces mesures ont été réalisées tous les deux jours depuis l'imposition de la contrainte hydrique à 08:00 AM, 01:00 PM et 05:30 PM. Le nombre de feuilles vertes et non wiltées a été déterminé en fin d'expérimentation. La surface de la plus jeune feuille complètement développée a été déterminée à l'aide du logiciel ImageJ $1.50 \mathrm{i}$ après avoir été prestement scannée. L'intégrité membranaire des cellules de la plus jeune feuille complètement développée a été analysée immédiatement après le scan en mesurant la conductivité des électrolytes qui fuient des cellules foliaires (EC) (Azooz, 2009). Brièvement, la plus jeune feuille totalement développée a été lavée à l'eau distillée puis découpée en petits morceaux de $1 \mathrm{~mm}$ de longueur qui ont ensuite été placés dans $10 \mathrm{ml}$ d'eau distillée et enfin laissés à température ambiante pendant $3 \mathrm{~h}$ avant que la conductivité de la solution $\mathbf{C}_{1}$ ne soit mesurée par un HI9813-6 Portable pH/EC/TDS/Temperature Meter (Hanna Instruments, Inc. USA). Ensuite, la conductivité a été à nouveau mesurée $\left(\mathrm{C}_{2}\right)$ après 2 min d'ébullition et refroidissement à température ambiante. Le pourcentage de fuite d'électrolytes, EC, a été calculé comme suit: $\mathrm{EC}=\mathrm{C}_{1} \times 100 / \mathrm{C}_{2}$. 
Les poids frais (FW) et sec (DW) (après 48 heures au four à $65^{\circ} \mathrm{C}$ ) des feuilles ont été utilisés pour calculer leur teneur relative en eau (RWC) selon la formule ci-après : RWC $=(F W-$ DW $) \times 100 / F W \quad($ Farhangi-

Abriz and Ghassemi-Golezani, 2018; Kaouther et al., 2013).

3.3 Analyses statistiques : Les résidus des données collectées n'étaient pas distribués selon la loi normale. Toutefois, avec le logiciel
XLSTAT 2018.1., les différences entre les effets des traitements ont été déterminées invariablement par le test non-paramétrique de Kruskal-Wallis, la robustesse de l'ANOVA classique et l'ANOVA de Welch. Le test de comparaison par paires de Fisher LSD ou de Dunn a suivi pour grouper les traitements à effet identique.

\section{$4 \quad$ RESULTATS}

4.1 Colonisation mycorhizienne: Les mycorhiziennes dans des racines de tomate et figures 2 à 5 montrent la présence de structures d'hévéa issues de substrats inoculés.

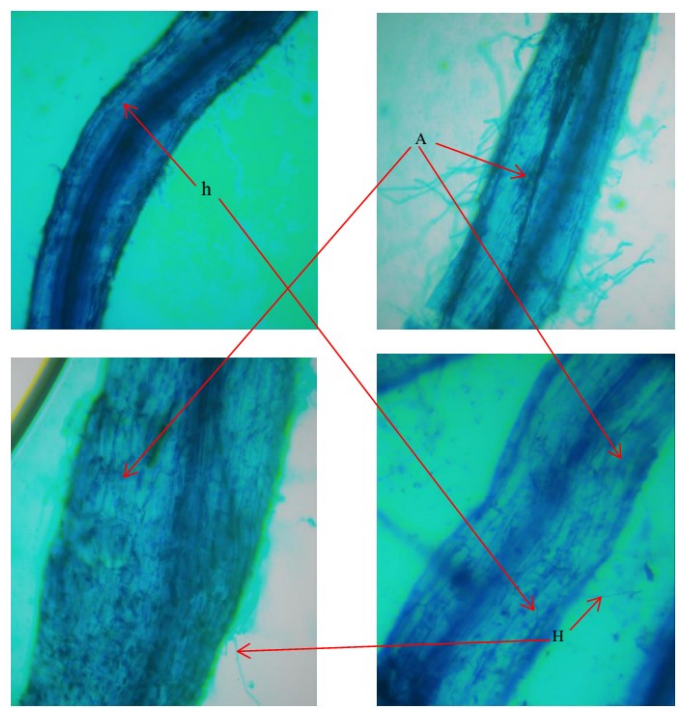

Figure 2. Structures mycorhiziennes des racines des plants de tomates issues de substrat contenant aussi IRCA331.

A : arbuscules ; $\mathrm{h}$ : hyphe intra racinaires ; $\mathrm{H}$ : hyphes extra racinaires $(\times 100)$.
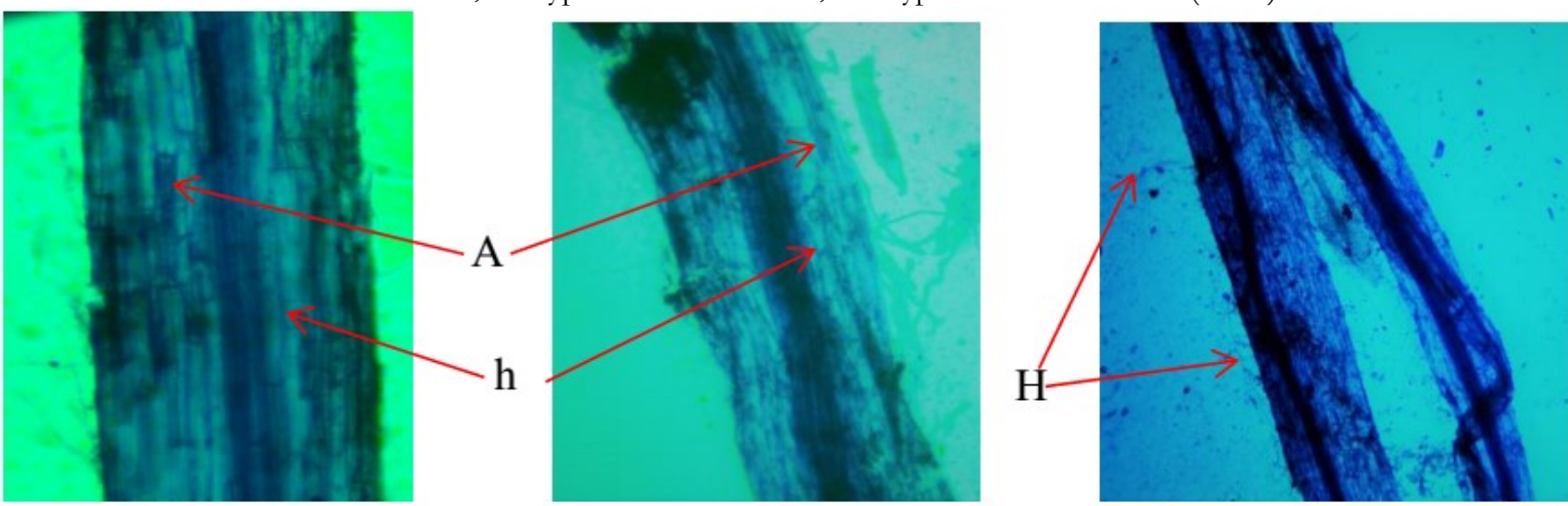

Figure 3. Structures mycorhiziennes des racines des plants de tomate, issues de substrat ne contenant que des pieds de tomate.

A : arbuscules ; $\mathrm{h}$ : hyphe intra racinaires ; $\mathrm{H}$ : hyphes extra racinaires $(\times 100)$. 

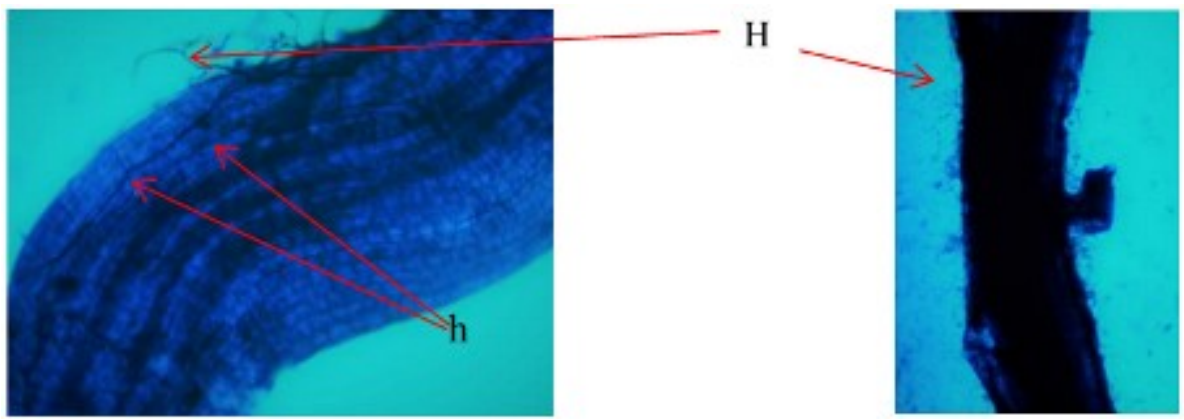

Figure 4. Structures mycorhiziennes des racines de IRCA331 issues de substrat contenant aussi de la tomate.

$\mathrm{h}$ : hyphe intra racinaires ; $\mathrm{H}$ : hyphes extra racinaires.
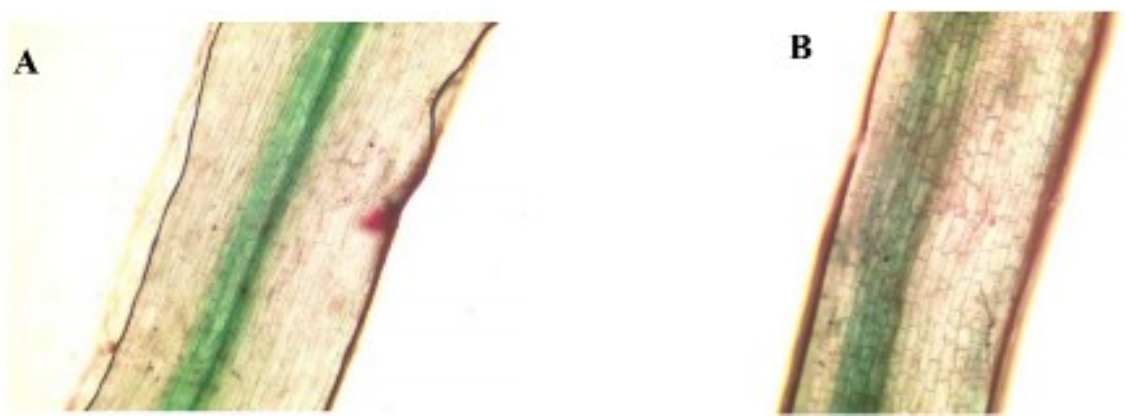

Figure 5. Structures mycorhiziennes des racines de tomate (A) et du porte-greffe GT1 du clone d'hévéa IRCA 331 (B) issues de substrat non inoculé.

Le porte-greffe GT1 avait une meilleure intensité de mycorhization que la tomate réputée mycotrophe (Figure 5). Les figures 2, 4 et 6 indiquent que les exsudats racinaires du type hévéine du porte-greffe du clone IRCA 331 n'entravent pas la colonisation de ses racines du clone d'hévéa et de celles de la tomate par R. irregularis DAOM 197198.

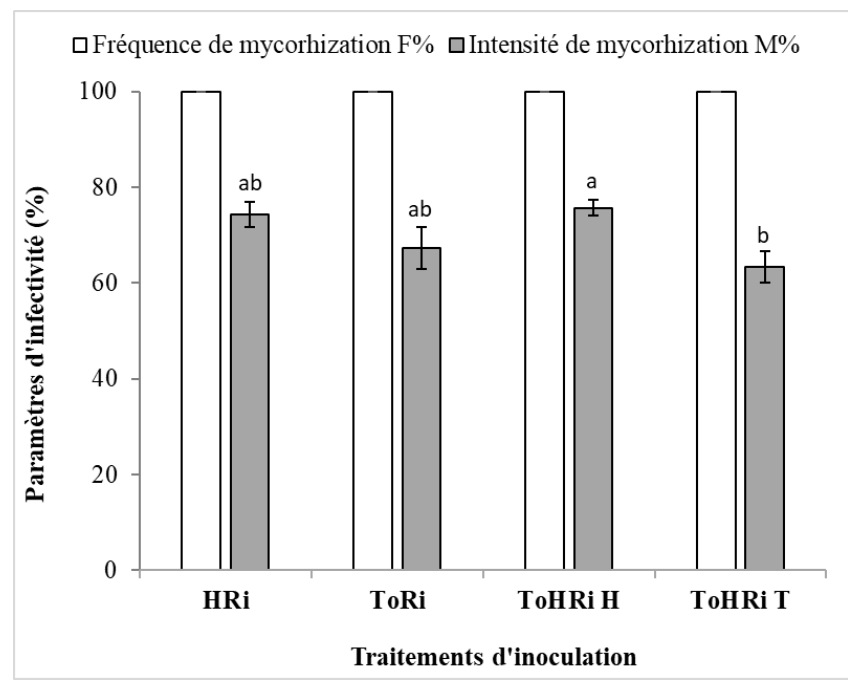

Figure 6. Infectivité mycorhizienne du porte-greffe du clone IRCA 331.

HRi : Inoculation de substrat ne contenant que des pieds d'hévéa. ToRi : Inoculation de substrat ne contenant que des pieds de tomate. ToHRi T et ToHRi H : Inoculation de substrat contenant à la fois des pieds de tomate et d'hévéa. Les 
barres représentant la moyenne de 10 mesures \pm écart-type, surmontées de différentes lettres sont significativement différentes $(\mathrm{p}=0.027)$.

Le porte-greffe GT1 a eu une meilleure abondance arbusculaire que la tomate réputée mycotrophe (Figure 6). Les figures 2, 4 et 7 montrent par l'abondance arbusculaire de $R$.

irregularis DAOM 197198 dans les racines que la mycorhization est fonctionnelle et pourrait procurer des bénéfices au clone IRCA 331.

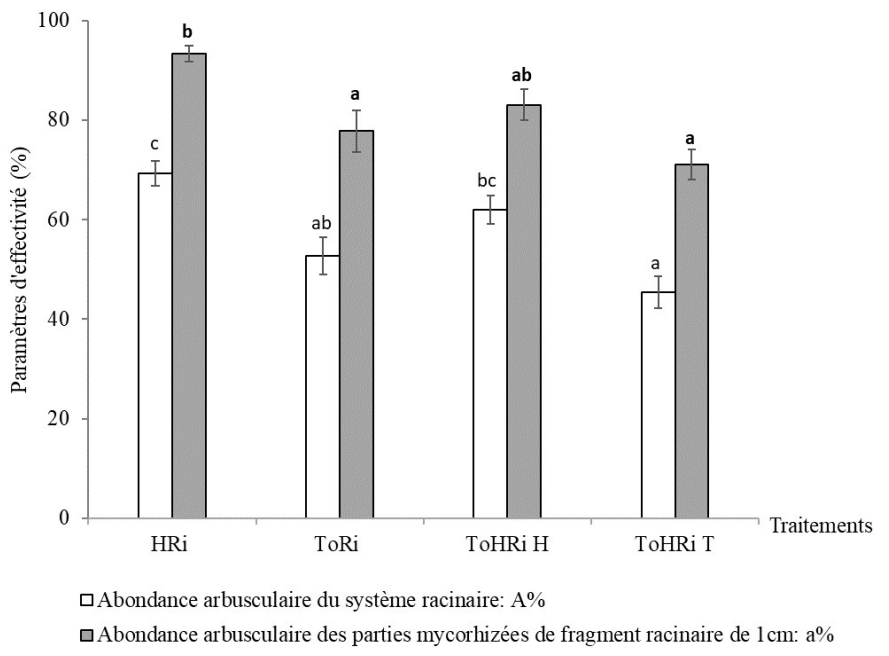

Figure 7. Évaluation de l'effectivité mycorhizienne du porte-greffe du clone IRCA 331.

HRi : Inoculation de substrat ne contenant que des pieds d'hévéa. ToRi : Inoculation de substrat ne contenant que des pieds de tomate. ToHRi T et ToHRi H : Inoculation de substrat contenant à la fois des pieds de tomate et d'hévéa. Les barres des traitements, représentant la moyenne de 10 mesures \pm écart type, surmontées de différentes lettres pour un paramètre donné sont très hautement significativement différentes $(\mathrm{p}=0.0054$ pour $\mathrm{a} \%$ et $\mathrm{p}=0.0024$ pour $\mathrm{A} \%)$.

\subsection{Effet différentiel des traitements sur} le clone IRCA 331 : Le phénotypage des plants IRCA 331 montre que les traitements ont différentiellement impacté leur croissance végétative. La croissance et l'aspect des plants s'est détérioré significativement avec la sévérité du stress quoique le clone IRCA 331 semble posséder une résilience native au stress hydrique moyennement sévère. Néanmoins, comparativement aux plants non mycorhizés, les plants mycorhizés se développent mieux et présentent un meilleur aspect végétatif (Figures 8 à 10). 


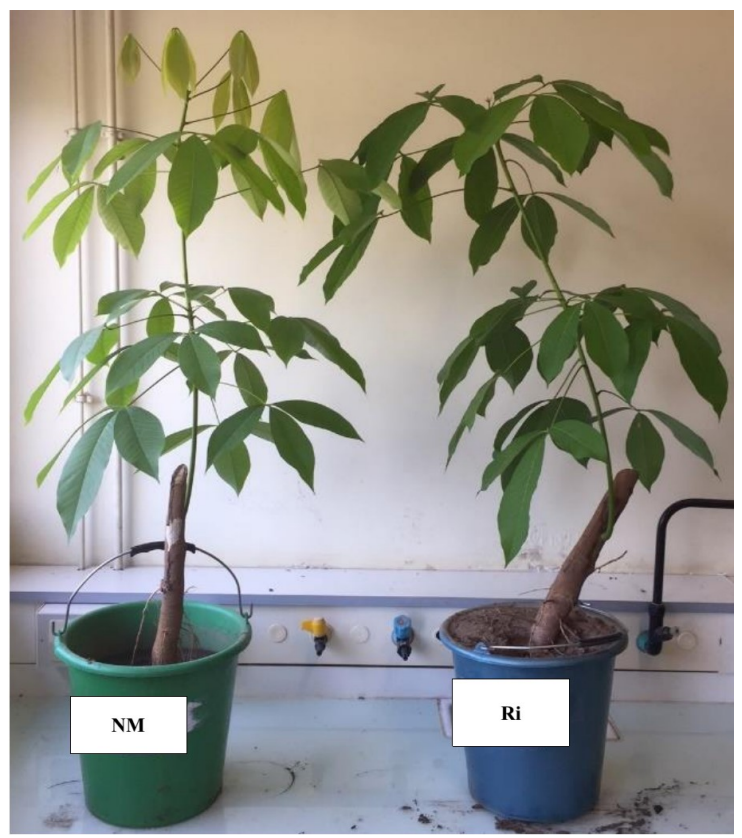

Figure 8. Plants IRCA 331 non-stressés photographiés à 14 jours post imposition du stress hydrique.

NM : Plants non mycorhizés cultivés dans un sol dont la teneur en eau a été nivelée journalièrement à $100 \%$ CR durant 14 jours ; Ri : Plants mycorhizés cultivés dans un sol dont la teneur en eau a été nivelée journalièrement à 100\% CR durant 14 jours.

La Figure 9 illustre bien que les plants mycorhizés ont un meilleur aspect que les plants non mycorhizés sous un stress hydrique moyennement sévère.

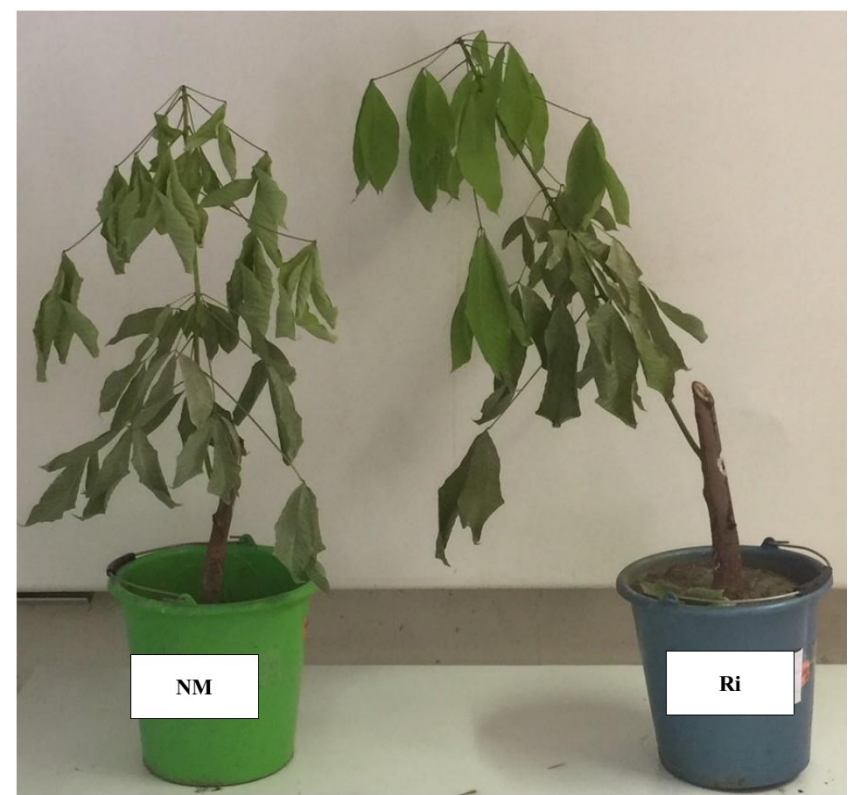

Figure 9. Plants IRCA 331 photographiés à 14 jours post imposition du stress hydrique moyennement sèvère.

NM : Plants non mycorhizés, cultivés dans un sol dont la teneur en eau a été nivelée journalièrement à $50 \%$ CR durant 14 jours ; Ri : Plants mycorhizés cultivés dans un sol dont la teneur en eau a été nivelée journalièrement à $50 \%$ CR durant 14 jours. 
La Figure 10 illustre bien que les plants mycorhizés ont un meilleur aspect que les plants non mycorhizés sous un stress hydrique sévère.

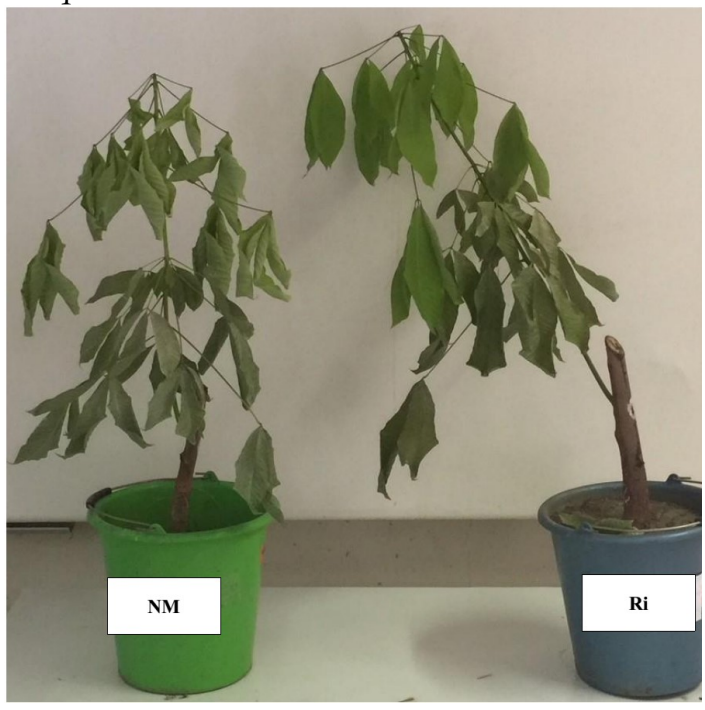

Figure 10. Plants IRCA 331 photographiés à 14 jours post imposition du stress hydrique sévère.

NM : Plants non mycorhizés sevrés d'eau pendant 14 jours (CR à 5\%); Ri : Plants mycorhizés sevrés d'eau pendant 14 jours (CR à $5 \%)$.

4.3 $\mathrm{pH}$ et humidité du substrat de culture : Le substrat utilisé a un $\mathrm{pH}$ neutre. Toutefois, le stress hydrique a tendance à le rendre plus alcalin. En effet, le $\mathrm{pH}$ du substrat portant des plants mycorhizés est plus basique $(7,43$ - 7,93) que celui des plants non mycorhizés $(7,13-7,80)$ (Figure 11).

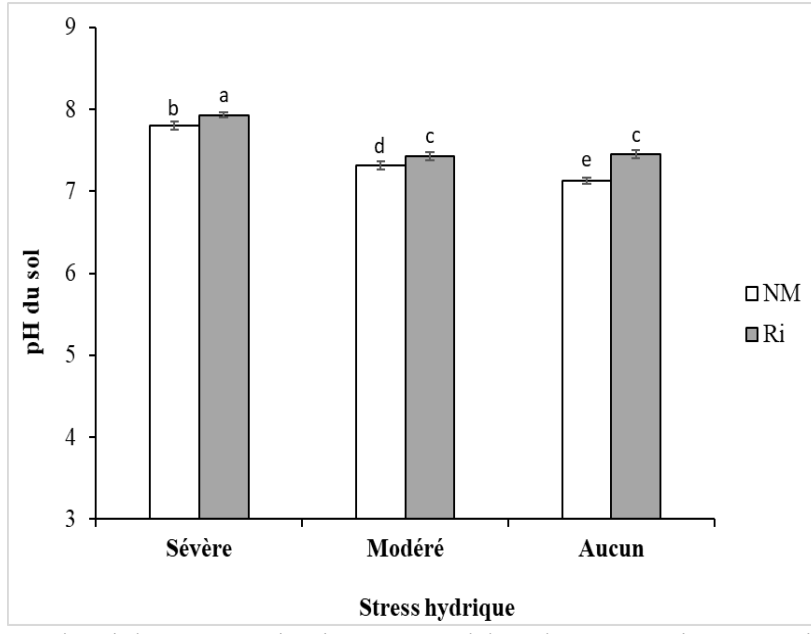

Figure 11. Effet du stress hydrique et de la mycorhization sur le $\mathrm{pH}$ du substrat à 42 jours après inoculation de CMA.

Les barres sont des moyennes de 12 mesures en fin d'expérimentation (42 jpi). Les barres d'une couleur donnée avec différentes lettres sont hautement significativement différentes $(\mathrm{p}<0,01)$. Les plants non mycorhizés (NM) et mycorhizés (Ri) ont été soumis à 28 jpi à un stress hydrique sévère $(5 \% \mathrm{CR})$, à un stress hydrique modéré $(50 \% \mathrm{CR})$ ou à aucun stress hydrique $(100 \% \mathrm{CR})$ durant 14 jours.

L'humidité du sol a diminué naturellement et de façon drastique avec le niveau de stress hydrique imposé. Le substrat portant les plantes mycorhizées a eu un meilleur taux d'humidité 
$(13,8-85,4)$ que celui des plantes non hydrique appliqué $(8,6-81,0)$ (Figure 12). mycorhizées quel que soit la sévérité du stress

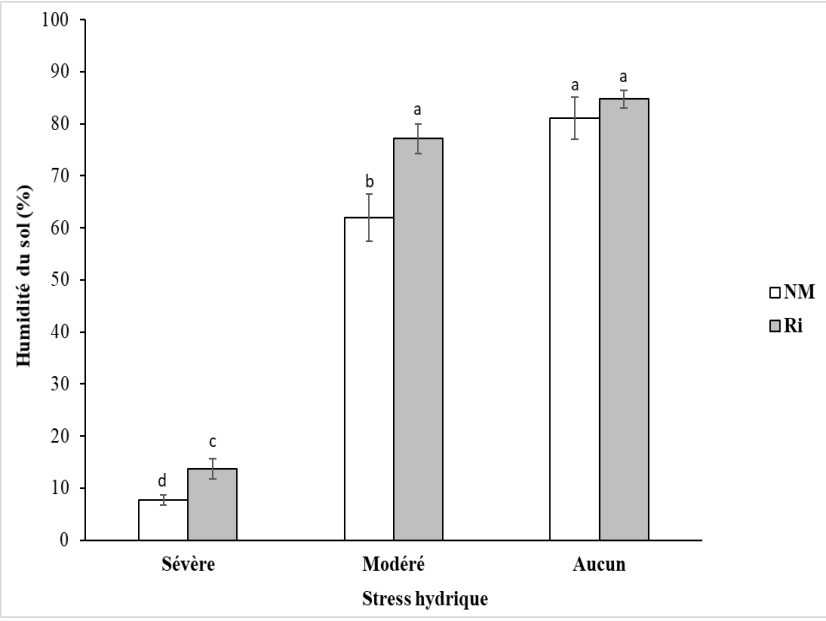

Figure 12. Effet du stress hydrique et de la mycorhization sur l'humidité du substrat à 42 jours post inoculation du CMA.

Les barres sont des moyennes de 12 mesures prises à 01:00PM en fin d'expérimentation (42 jpi). Les barres d'une couleur donnée avec différentes lettres sont hautement significativement différentes $(p<0,01)$. Les plants non mycorhizés $(\mathrm{NM})$ et mycorhizés (Ri) ont été soumis à 28 jpi à un stress hydrique sévère ( $5 \% \mathrm{CR})$, à un stress hydrique modéré $(50 \% \mathrm{CR})$ ou à aucun stress hydrique $(100 \% \mathrm{CR})$ durant 14 jours.

\subsection{Indice de réflectance photochimique} (PRI) : L'indice de réflectance photochimique (PRI) est positivement corrélé à l'utilisation efficiente de la lumière ou radiation photosynthétique (LUE ou RUE). Le PRI ou
RUE des plants mycorhizés est 1,58 fois supérieure à celui des plants non mycorhizés au moment le plus ensoleillé de la journée (Figure 13).

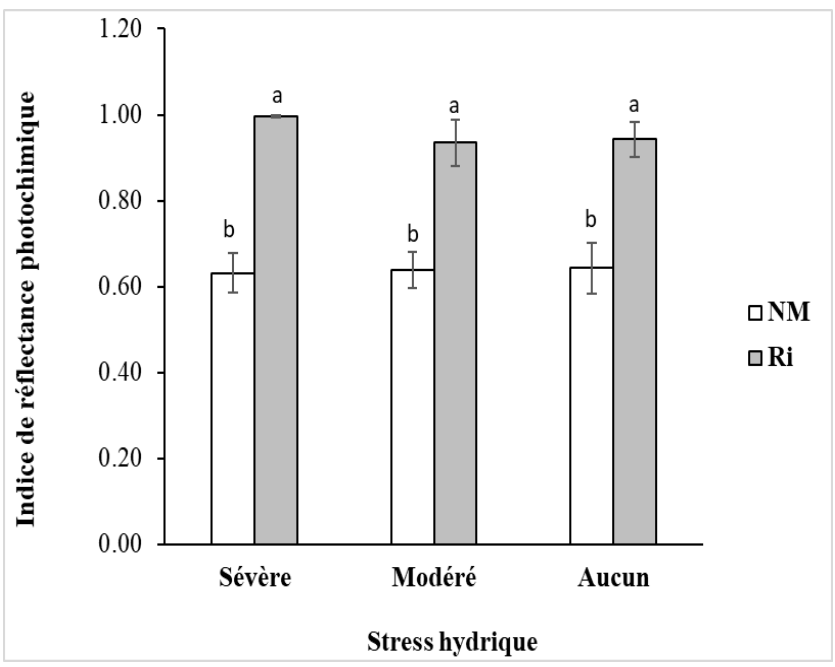

Figure 13. Effet du stress hydrique et de la mycorhization sur l'indice de reflectance photochimique. Les barres sont des moyennes de 12 mesures prises à 01:00PM en fin d'expérimentation (42 jpi). Les barres d'une couleur donnée avec différentes lettres sont hautement significativement différentes $(p<0,01)$. Les plants non mycorhizés $(\mathrm{NM})$ et mycorhizés (Ri) ont été soumis à 28 jpi à un stress hydrique sévère $(5 \% \mathrm{CR})$, à un stress hydrique modéré $(50 \% \mathrm{CR})$ ou à aucun stress hydrique $(100 \% \mathrm{CR})$ durant 14 jours. 
4.5 Température foliaire: Les plants mycorhizés ont eu une température foliaire $\left(34,5-347^{\circ} \mathrm{C}\right)$ significativement inférieure à celle des plants non mycorhizées (36,2 $36,6^{\circ} \mathrm{C}$ ) quel que soit le niveau de stress (Figure $14)$.

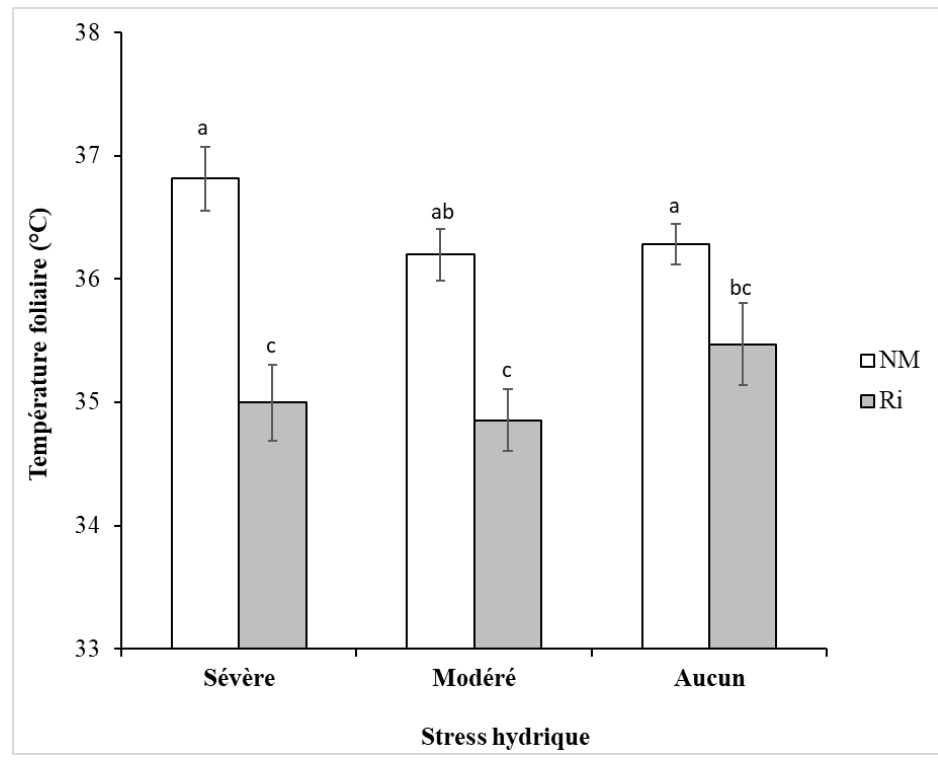

Figure 14. Effet du stress hydrique et de la mycorhization sur la température foliaire.

Les barres sont des moyennes de 12 mesures prises à 01:00PM en fin d'expérimentation (42 jpi). Les barres d'une couleur donnée avec différentes lettres sont hautement significativement différentes $(p<0,01)$. Les plants non mycorhizés $(\mathrm{NM})$ et mycorhizés $(\mathrm{Ri})$ ont été soumis à 28 jpi à un stress hydrique sévère $(5 \% \mathrm{CR})$, à un stress hydrique modéré $(50 \% \mathrm{CR})$ ou à aucun stress hydrique $(100 \% \mathrm{CR})$ durant 14 jours.

\subsection{Nombre de feuilles vertes et surfaces}

foliaires : Le nombre de feuilles vertes et non wiltées des plantes mycorhizées $(8,5)$ sont significativement supérieurs à celui des plantes témoins $(5,1)$ en condition de stress hydrique sevère (Figure 15).

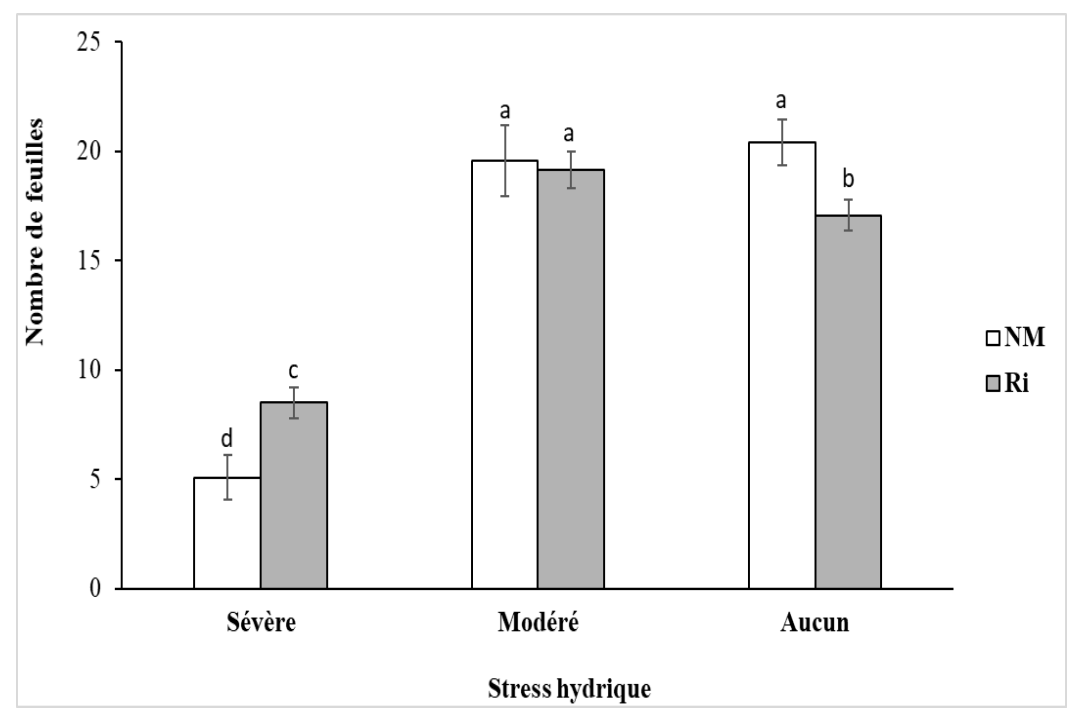

Figure 15. Effet du stress hydrique et de la mycorhization sur le développement foliaire.

Les barres sont des moyennes de 12 mesures en fin d'expérimentation (42 jpi). Les barres d'une couleur donnée avec différentes lettres sont hautement significativement différentes $(\mathrm{p}<0,01)$. Les plants non mycorhizés $(\mathrm{NM})$ et 
mycorhizés (Ri) ont été soumis à 28 jpi à un stress hydrique sévère ( $5 \% \mathrm{CR})$, à un stress hydrique modéré $(50 \% \mathrm{CR})$ ou à aucun stress hydrique $(100 \% \mathrm{CR})$ durant 14 jours.

L'examen des surfaces foliaires montre un effet différentiel des traitements. La mycorhization a contribué à une augmentation significative de la surface foliaire $\left(238,57 \mathrm{~cm}^{2}\right.$ contre $\left.177,43 \mathrm{~cm}^{2}\right)$ sous le stress hydrique modéré (Figure 16).

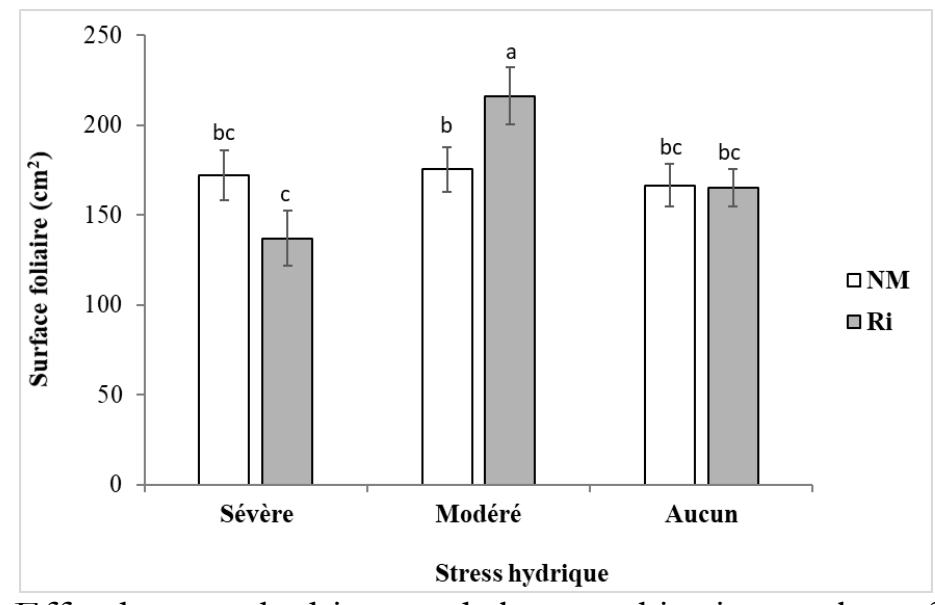

Figure 16. Effet du stress hydrique et de la mycorhization sur la surface foliaire.

Les barres sont des moyennes de 12 mesures en fin d'expérimentation (42 jpi). Les barres d'une couleur donnée avec différentes lettres sont hautement significativement différentes $(\mathrm{p}<0,01)$. Les plants non mycorhizés (NM) et mycorhizés (Ri) ont été soumis à 28 jpi à un stress hydrique sévère $(5 \% \mathrm{CR})$, à un stress hydrique modéré $(50 \% \mathrm{CR})$ ou à aucun stress hydrique $(100 \% \mathrm{CR}) 14$ durant jours.

4.7 Évolution des mensurations de la tige issue du greffon: Il ressort de l'analyse statistique que la mycorhization n'améliore significativement ces paramètres qu'en conditions de stress hydrique sévère, où ce gain est approximativement le double de celui des plants non mycorhizés (Figures 17 et 18).

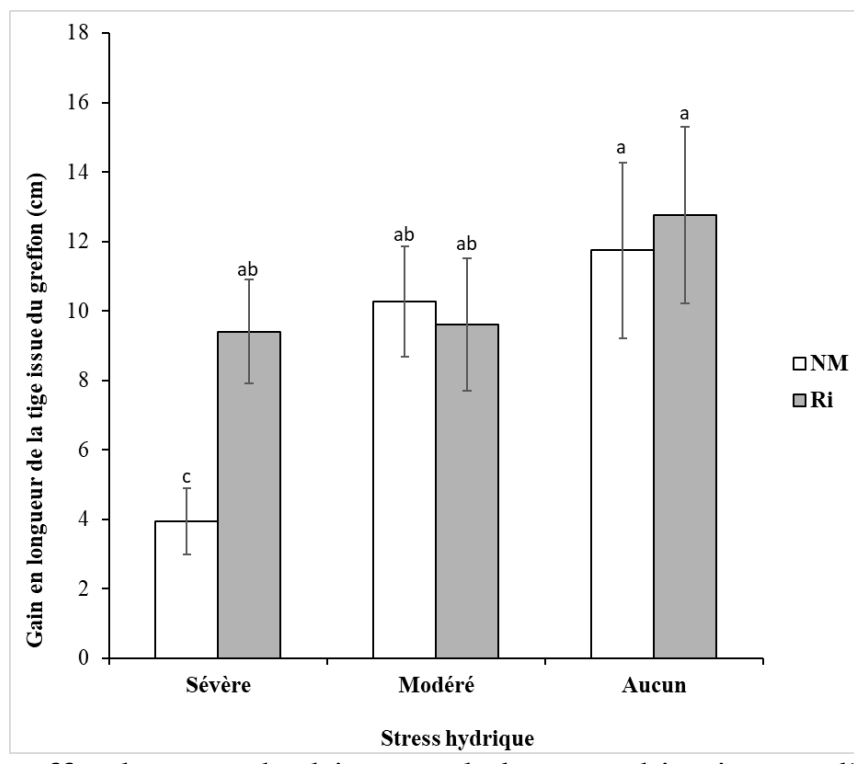

Figure 17. Effet du stress hydrique et de la mycorhization sur l'élongation..

Les barres sont des moyennes de 12 mesures en fin d'expérimentation (42 jpi). Les barres d'une couleur donnée avec différentes lettres sont significativement différentes $(\mathrm{p}=0,038)$. Les plants non mycorhizés $(\mathrm{NM})$ et mycorhizés $(\mathrm{Ri})$ ont 
été soumis à 28 jpi à un stress hydrique sévère (5\% CR), à un stress hydrique modéré $(50 \% \mathrm{CR})$ ou à aucun stress hydrique $(100 \% \mathrm{CR})$ durant 14 jours.

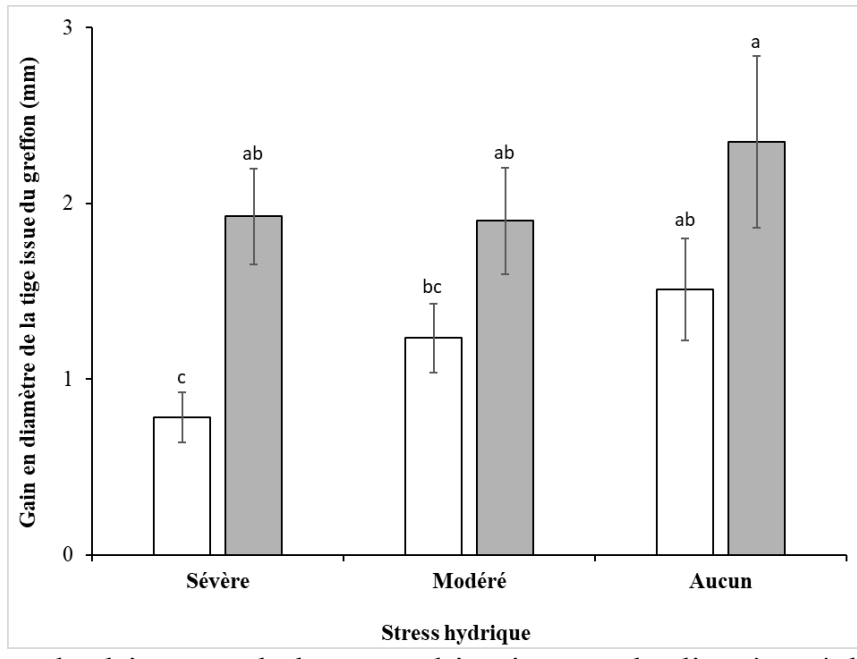

Figure 18. Effet du stress hydrique et de la mycorhization sur le diamètre à la base de la tige issue du greffon.

Les barres sont des moyennes de 12 mesures en fin d'expérimentation (42 jpi). Les barres d'une couleur donnée avec différentes lettres sont hautement significativement différentes $(\mathrm{p}<0,01)$. Les plants non mycorhizés (NM) et mycorhizés (Ri) ont été soumis à 28 jpi à un stress hydrique sévère $(5 \% \mathrm{CR})$, à un stress hydrique modéré $(50 \% \mathrm{CR})$ ou à aucun stress hydrique $(100 \% \mathrm{CR})$ durant 14 jours.

4.8 Teneur en chlorophylle et fuite des électrolytes des cellules foliaires : Les teneurs en chlorophylle des plants mycorhizés $(35,13-48,52$ unités SPAD) étaient significativement plus élevées que celles des plants non-mycorhizés (31,33 - 42,18 unités SPAD) (Figure 19).

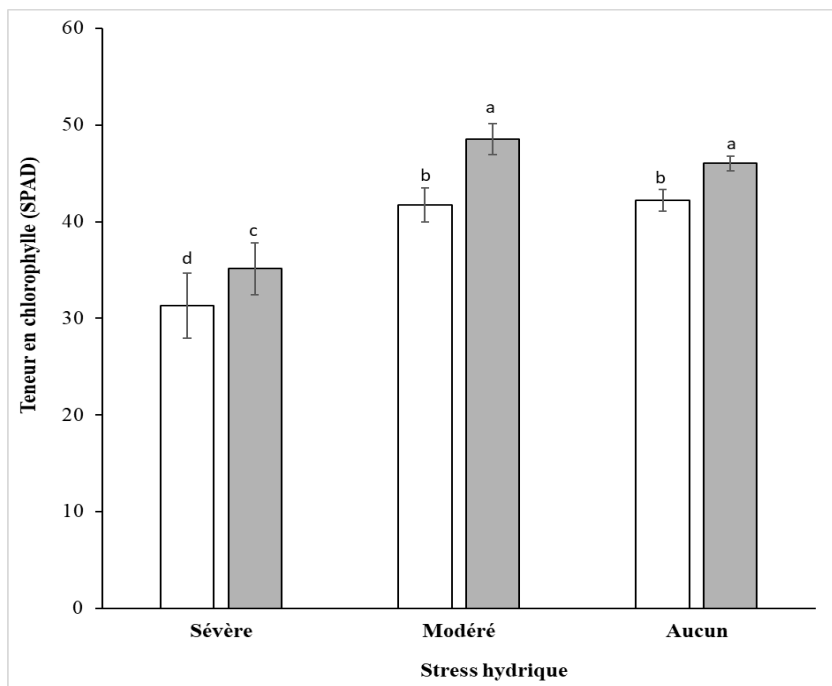

Figure 19. Effet du stress hydrique et de la mycorhization sur la teneur en chlorophylle.

Les barres sont des moyennes de 12 mesures en fin d'expérimentation (42 jpi). Les barres d'une couleur donnée avec différentes lettres sont significativement différentes $(\mathrm{p}<0,05)$. Les plants non mycorhizés (NM) et mycorhizés (Ri) ont été soumis à 28 jpi à un stress hydrique sévère $(5 \% \mathrm{CR})$, à un stress hydrique modéré $(50 \% \mathrm{CR})$ ou à aucun stress hydrique $(100 \%$ CR) durant 14 jours. 
La conductivité chez les plants mycorhizés était plants non mycorhizés quel que soit la severité significativement plus basse ( que celle des du stress hydrique (Figure 20).

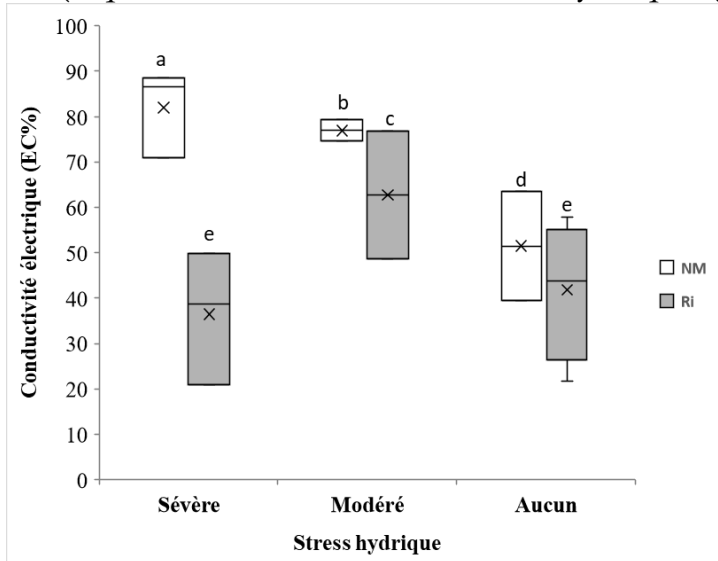

Figure 20. Effet du stress hydrique et de la mycorhization sur la fuite d'électrolytes des cellules foliaires.

Les barres sont des moyennes de 12 mesures en fin d'expérimentation (42 jpi). Les barres d'une couleur donnée avec différentes lettres sont significativement différentes $(\mathrm{p}<0,05)$. Les plants non mycorhizés $(\mathrm{NM})$ et mycorhizés $(\mathrm{Ri})$ ont été soumis à 28 jpi à un stress hydrique sévère $(5 \% \mathrm{CR})$, à un stress hydrique modéré $(50 \% \mathrm{CR})$ ou à aucun stress hydrique (100\% CR) durant 14 jours.

\subsection{Biomasse sèche et teneur relative en} eau des feuilles; La biomasse foliaire sèche était statistiquement identique entre plants non mycorhizés $(7,3-13,4 \mathrm{~g})$ et plants mycorhizés $(4,9-12,7 \mathrm{~g})$ quel que soit le niveau de stress hydrique (Figure 21).

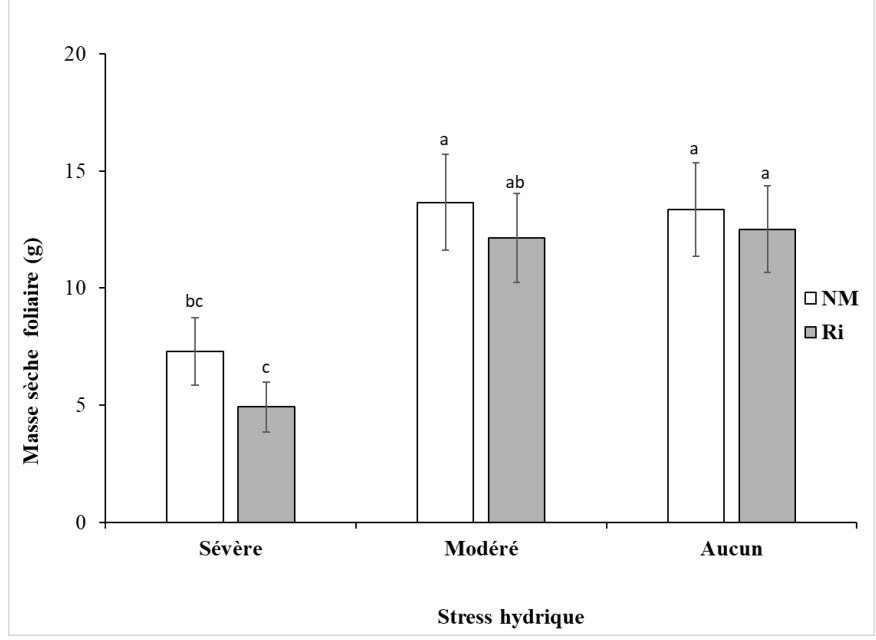

Figure 21. Effet du stress hydrique et de la mycorhization sur la biomasse sèche foliaire.

Les barres sont des moyennes de 12 mesures en fin d'expérimentation (42 jpi). Les barres d'une couleur donnée avec différentes lettres sont significativement différentes $(\mathrm{p}<0,05)$. Les plants non mycorhizés $(\mathrm{NM})$ et mycorhizés $(\mathrm{Ri})$ ont été soumis à $28 \mathrm{jpi}$ à un stress hydrique sévère $(5 \% \mathrm{CR})$, à un stress hydrique modéré $(50 \% \mathrm{CR})$ ou à aucun stress hydrique $(100 \% \mathrm{CR})$ durant 14 jours.

En conditions d'alimentation hydrique très réduite, la mycorhization a conduit à une bien meilleure teneur en eau des feuilles (59,30\%) comparativement aux feuilles des plants non mycorhizés (35,90\%) (Figure 22). 


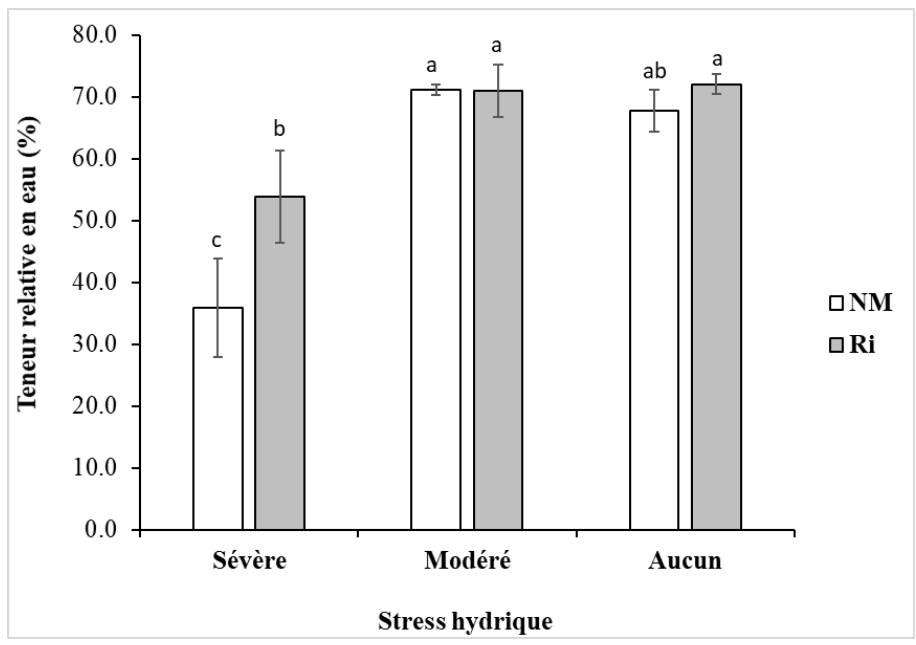

Figure 22. Effet du stress hydrique et de la mycorhization sur la teneur en eau.

Les barres sont des moyennes de 12 mesures en fin d'expérimentation (42 jpi). Les barres d'une couleur donnée avec différentes lettres sont hautement significativement différentes $(\mathrm{p}<0,01)$. Les plants non mycorhizés (NM) et mycorhizés (Ri) ont été soumis à 28 jpi à un stress hydrique sévère $(5 \% \mathrm{CR})$, à un stress hydrique modéré $(50 \% \mathrm{CR})$ ou à aucun stress hydrique $(100 \% \mathrm{CR})$ durant 14 jours.

\section{$5 \quad$ DISCUSSION}

L'observation microscopique des racines du porte-greffe GT1 et de celles de la tomate, cultivés dans un même substrat, contenant des spores mycorhiziennes inoculées dans le système racinaire de GT1, a révélé la présence typique de structures mycorhiziennes telles que des hyphes extra et intracellulaires et des arbuscules. Le statut mycorhizien du portegreffe GT1 est donc établi : il peut établir une symbiose mycorhizienne fonctionnelle avec une très bonne intensité de mycorhization $(>70 \%)$ et abondance arbusculaire $(>60 \%)$. Ce qui suggère que $R$. irregularis DAOM 197198 possèderait un mécanisme de résistance ou mieux de détoxification des exsudats antifongiques du type hévéine. Bien que contraire aux résultats in vitro sur le clone $\mathrm{PB}$ 260 par la souche Rhizophagus irregularis MUCL 41833 obtenus par (Slavokhotova et al., 2014; Sosa Rodriguez et al., 2013; Van Parijs et al., 1991), nos résultats confortent ceux d'autres chercheurs. En effet, ceux-ci ont plutôt observé un bon pourcentage de colonisation (> 60\%) des clones RRIM par des isolats de Glomus et/ou d'Acaulospora (Basumatary et al., 2014; Herrmann et al., 2016). Il nous semble que ces résultats contrastés soient fonction du génotype d’hévéa et/ou des isolats mycorhiziens utilisés.
Il serait nécessaire d'étudier les mécanismes de résistance aux antifongiques du type hévéine qui sous-tendent l'établissement de la symbiose chez l'hévéa. L'humidité du sol de culture a baissé naturellement et de façon drastique avec le niveau de stress hydrique imposé. Elle varie évidemment avec la température et l'humidité relative de l'air ambiant. Toutefois, le substrat portant les plantes mycorhizées avait un meilleur taux d'humidité que celui des plantes non mycorhizées quel que soit la sévérité du stress hydrique appliqué. La mycorhization participerait ainsi à une meilleure rétention d'eau dans le sol. Il est bien documenté que les hyphes extraracinaires mycorhiziens produisent de la glomaline, une protéine qui augmente la stabilité et l'agrégation des particules du sol de sorte à augmenter sa capacité de rétention d'eau (Li et al., 2015; Martín-Robles et al., 2018; Morris et al., 2019; Rillig et al., 2015; Rillig and Mummey, 2006; Wu et al., 2008, 2014). Fait intéressant qui contribuerait à la résistance des plants mycorhizés au stress hydrique. La plante souffre de stress hydrique surtout quand l'eau absorbée pour ses fonctions métaboliques, est en grande partie perdue par transpiration au niveau des feuilles. Généralement, les feuilles transpirent pour refroidir leur surface foliaire. 
Ainsi, la température foliaire est un indice du niveau de stress hydrique et même thermique subit par la plante (Debona et al., 2017). L'analyse des réponses du clone mycorhizé aux régimes hydriques a révélé une réduction significative de la température foliaire, de la fuite d'électrolytes des cellules foliaires, et une augmentation significative de l'indice de réflectance photochimique donc de l'efficience de la lumière photosynthétique, comparativement aux plants non mycorhizés. Ces trois phenomenes suggèrent que la mycorhization contribue non seulement à améliorer significativement la tolérance ou la résistance du clone IRCA 331 au stress hydrique mais aussi au stress oxydatif (sous réserve de l'analyse comparée de l'activité enzymatique et non enzymatique antioxydante) et au stress thermique, donc à la sècheresse. Les teneurs en chlorophylle des plants mycorhizés, significativement plus élevées que les plants non mycorhizés, jointes aux constats susmentionnés, indiquent que $R$. irregularis DAOM 197198 améliore l'activité photosynthètique chez l'hévéa, même en cas de stress sévère. La mycorhization a significativement protégé la chlorophylle de la dégradation, comparativement aux plantes non mycorhizées sous la contrainte hydrique. L'amélioration de la photosynthèse se répercute en gain de biomasse, d'élongation et de croissance en épaisseur (donc du cubage de bois). (Basumatary et al., 2014). Par ailleurs, la mycorhization du porte-greffe du clone IRCA 331 a amélioré significativement la teneur relative en eau des plants, donc la capacité d'absorption de l'eau et la réduction de la transpiration. Ainsi, la mycorhization pourrait

\section{CONCLUSION}

De cette étude, il ressort que le porte-greffe GT1 est bien mycotrophe. L'évaluation a révélé d'excellents résultats en ce qui concerne les paramètres d'infectivité et d'effectivité de $R$. irregularis DAOM 197198. Le CMA possèderait un mécanisme de résistance (peut-être de détoxification) vis-à-vis des substances de type hévéine. R. irregularis DAOM 197198 a participer la réduction des zones marginales à la culture d'hévéa due la raréfaction ou à la mauvaise répartition des pluies de plus en plus marquée par le changement climatique. L'ensemble des données de phénotypage des plants IRCA 331 daans la présente étude montre que les traitements ont différentiellement impacté leur développement végétatif. Il est intéressant de relever que les plants non mycorhizés, soumis au stress modéré, témoignent d'une résilience propre. Toutefois, les plants mycorhizés se développent mieux et présentent un meilleur aspect végétatif et un meilleur indice de réflectance photochimique (PRI). Il est bien connu que les CMA renforcent la résilience des plantes face aux stress environnementaux tels que le déficit en eau. (Pioufle and Declerck, 2018). Bien que les effets bénéfiques de CMA sur les plantes soumises à un stress hydrique aient été rapportés par plusieurs auteurs (Hamza, 2014; Recchia et al., 2018), cette étude est la première à signaler l'impact positive sur le PRI. Le PRI est positivement corrélé aux changements dans les pigments caroténoïdes qui indiquent des changements dans l'efficacité d'utilisation de la lumière ou de la radiation photosynthétique (LUE ou RUE), le taux d'absorption du $\mathrm{CO}_{2}$ par unité d'énergie absorbée et comme indice fiable du stress hydrique (Gamon et al., 1997; Garbulsky et al., 2011; Peñuelas et al., 2011, 2013). Cela suggère que l'utilisation de CMA pourrait représenter une approche innovante pour résoudre le problème du déclin de la production hévéicole dans des conditions de sécheresse. Toutefois, ces résultats doivent être confirmés par des tests au champ.

significativement boosté le PRI, et la teneur en chlorophylle même en cas de stress sévère. Elle a également induit une amélioration les capacités de rétention en eau du sol et des feuilles. Au regard de ces résultats, la mycorhization pourrait participer à réduire la marginalisation des zones à la culture d'hévéa liée au manque d'eau. Ainsi, il est possible 
d'améliorer la productivité agricole par la promotion des champignons mycorhiziens pour faire face à l'intensification de la sécheresse due au changement climatique, mais aussi, et surtout, pour la réduction des dépenses liées à l'irrigation.

\section{REFERENCES BIBLIOGRAPHIQUES}

Azooz MM : 2009. Salt stress mitigation by seed priming with salicylic acid in two faba bean genotypes differing in salt tolerance. International Journal of Agriculture and Biology, 11: 343-350.

Basu S, Rabara RC. and Negi S : 2018. AMF: The future prospect for sustainable agriculture. Physiological and Molecular Plant Pathology, 102: 36-45. https://doi.org/10.1016/j.pmpp.2017.1 1.007

Basumatary N, Parkash V, Tamuli AK, Saikia AJ, and Teron R : 2014. Arbuscular mycorrhizal inoculation affects growth and rhizospheric nutrient availability in Hevea brasiliensis (Willd. ex A. Juss.) Mull. Arg. clones. International Journal of Current Biotechnology, 2: 14-21.

Chitarra W, Pagliarani C, Maserti B, Lumini E, Siciliano I, Cascone P, Schubert A, Gambino G, Balestrini R. and Guerrieri $\mathrm{E}:$ 2016. Insights on the Impact of Arbuscular Mycorrhizal Symbiosis on Tomato Tolerance to Water Stress. Plant Physiology, 171: 1009-1023. https://doi.org/10.1104/pp.16.00307

Choon Koo J, Jin Chun H, Cheol Park H, Chul Kim M., Duck Koo Y, Cheol Koo S, Mi Ok H, Jeong Park S, Lee S-H, Yun D-J, Oh Lim C, Dong Bahk J, Yeol Lee S. and Cho MJ, 2002. Over-expression of a seed specific hevein-like antimicrobial peptide from Pharbitis nil enhances resistance to a fungal pathogen in transgenic tobacco plants. Plant Molecular Biology, 50: 441-452. https://doi.org/10.1023/A:1019864222 515

Debona D, Rodrigues FA. and Datnoff LE : 2017. Silicon's Role in Abiotic and Biotic Plant Stresses. Annual Review of Phytopathology, 55: 85-107. https://doi.org/10.1146/annurevphyto-080516-035312

Farhangi-Abriz S. and Ghassemi-Golezani K : 2018. How can salicylic acid and jasmonic acid mitigate salt toxicity in soybean plants? Ecotoxicology and Environmental Safety, 147: 1010-1016. https://doi.org/10.1016/j.ecoenv.2017. 09.070

Fotso B, Nandjui J, Bi Voko DRR, Amoa AJ. and Niemenak $\mathrm{N}$ : 2019. Native arbuscular mycorrhizal fungi increased resistance of two plantain varieties (Fhia 21 and Orishele), under water deficit conditions in Cote d'Ivoire. Microbiology and Nature, 1: 16-28. https://doi.org/10.26167/xxwd-j920

Gamon JA, Serrano L. and Surfus JS : 1997. The photochemical reflectance index: an optical indicator of photosynthetic radiation use efficiency across species, functional types, and nutrient levels. Oecologia 112: 492-501. https://doi.org/10.1007/s00442005033 7

Garbulsky MF, Peñuelas J, Gamon J, Inoue Y. and Filella I : 2011. The photochemical reflectance index (PRI) and the remote sensing of leaf, canopy and ecosystem radiation use efficiencies: A review and meta-analysis. Remote Sensing of Environment, $\quad 115:$ 281-297. https://doi.org/10.1016/j.rse.2010.08.0 23

Guillemin JP, Gianinazzi S. and Trouvelot A : 1992. Screening of arbuscular endomycorrhizal fungi for establishment of micropropagated pineapple plants. Agronomie 12: 831836.

Hamza N : 2014. Application des mycorhizes arbusculaires en culture maraîchère cas de la pastèque (Citrullus lanatus) 
(mémoire). Université Ferhat Abbas

Sétif 1 Faculté des Sciences de la Nature et de la Vie.

Herrmann L, Bräu L, Robin A, Robain H, Wiriyakitnateekul W. and Lesueur D : 2016. High colonization by native arbuscular mycorrhizal fungi (AMF) of rubber trees in small-holder plantations on low fertility soils in North East Thailand. Arcbives of Agronomy and Soil Science, $\quad$ 62: 1041-1048. https://doi.org/10.1080/03650340.201 5.1110238

Hu W, Zhang H, Chen H. and Tang M : 2017. Arbuscular mycorrhizas influence Lycium barbarum tolerance of water stress in a hot environment. Mycorrbiza 27: $451-463$. https://doi.org/10.1007/s00572-0170765-0

Kang Y, Khan S. and Ma X : 2009. Climate change impacts on crop yield, crop water productivity and food security A review. Prog. Nat. Sci. 19: 1665-1674. https://doi.org/10.1016/j.pnsc.2009.08 .001

Kaouther Z, Nina H, Rezwan A. and Cherif H : 2013. Evaluation of salt tolerance $(\mathrm{NaCl})$ in Tunisian chili pepper (Capsicum frutescens L.) on growth, mineral analysis and solutes synthesis. $J$. Stress Physiol. Biochem. 9(1): 209-228

Li Z, Wu N, Liu T, Chen H. and Tang M : 2015. Effect of arbuscular mycorrhizal inoculation on water status and photosynthesis of Populus cathayana males and females under water stress. Physiologia Plantarum, 155: 192-204. https://doi.org/10.1111/ppl.12336

Macedo AF : 2012. Abiotic Stress Responses in Plants: Metabolism to Productivity, in: Abiotic Stress Responses in Plants: Metabolism, Productivity and Sustainability. pp. pp41-55.

Martín-Robles N, Lehmann A, Seco E, Aroca R, Rillig MC, and Milla R : 2018. Impacts of domestication on the arbuscular mycorrhizal symbiosis of 27 crop species. New Phytologist, 218: 322334. https://doi.org/10.1111/nph.14962

Morris EK, Morris DJP, Vogt S, Gleber SC, Bigalke M, Wilcke W. and Rillig MC : 2019. Visualizing the dynamics of soil aggregation as affected by arbuscular mycorrhizal fungi. The ISME Journal, 13(7): 1639-1646.

https://doi.org/10.1038/s41396-0190369-0

Noonan J, Williams WP. and Shan X : 2017. Investigation of Antimicrobial Peptide Genes Associated with Fungus and Insect Resistance in Maize. International Journal of Molecular Sciences, 18(9): 1938. https://doi.org/10.3390/ijms18091938

Peñuelas J, Garbulsky MF. and Filella I : 2011. Photochemical reflectance index (PRI) and remote sensing of plant $\mathrm{CO}_{2}$ uptake. New Phytologist, 191: 596-599. https://doi.org/10.1111/j.14698137.2011.03791.x

Peñuelas J, Marino G, LLusia J, Morfopoulos C, Farré-Armengol G. and Filella I : 2013. Photochemical reflectance index as an indirect estimator of foliar isoprenoid emissions at the ecosystem level. Nature Communications, 4: 2604. https://doi.org/10.1038/ncomms3604

Phillips JM. and Hayman DS : 1970. Improved procedures for clearing roots and staining parasitic and vesiculararbuscular mycorrhizal fungi for rapid assessment of infection. Transactions of the British Mycological Society, 55: 158IN18. https://doi.org/10.1016/S00071536(70)80110-3

Pioufle OL. and Declerck S : 2018. Reducing Water Availability Impacts the Development of the Arbuscular Mycorrhizal Fungus Rhirophagus irregularis MUCL 41833 and Its Ability to Take Up and Transport Phosphorus Under in Vitro Conditions. Frontiers in Microbiology, $\quad 9$ : 1254. https://doi.org/10.3389/fmicb.2018.01 254 
Recchia GH, Konzen ER, Cassieri F, Caldas DGG. and Tsai SM : 2018. Arbuscular Mycorrhizal Symbiosis Leads to Differential Regulation of DroughtResponsive Genes in Tissue-Specific Root Cells of Common Bean. Frontiers in Microbiology, 9:1339. https://doi.org/10.3389/fmicb.2018.01 339

Rillig MC, Aguilar-Trigueros CA, Bergmann J, Verbruggen E, Veresoglou SD. and Lehmann A : 2015. Plant root and mycorrhizal fungal traits for understanding soil aggregation. New Phytologist, 205: 1385-1388. https://doi.org/10.1111/nph.13045

Rillig MC. and Mummey DL : 2006. Mycorrhizas and soil structure. New Phytologist, $\quad$ 171: 41-53. https://doi.org/10.1111/j.14698137.2006.01750.x

Sahraoui A : 2013. La Mycorhize à arbuscules : quels bénéfices pour l'homme et son environnement dans un contexte de développement durable? Synthèse: Revue des Sciences et de la Technologie, 26: 06-19.

Slavokhotova AA, Naumann TA, Price NPJ, Rogozhin EA, Andreev YA, Vassilevski AA. and Odintsova TI : 2014. Novel mode of action of plant defense peptides - hevein-like antimicrobial peptides from wheat inhibit fungal metalloproteases. FEBS Journal, 281: 4754-4764.

https://doi.org/10.1111/febs.13015

Sosa Rodriguez T, Declerck S, Granet F, Gaurel S, Damme EMJV. and Dupré De Boulois H : 2013. Hevea brasiliensis and Urtica dioica impact the in vitro mycorrhization of neighbouring
Medicago truncatula seedlings. Symbiosis 60(3): 123-132.

Trouvelot A, Kough J. and Gianinazzi-Pearson $\mathrm{V}:$ 1986. Evaluation of VA infection levels in root systems. Research for estimation methods having a functional significance. Physiological and genetical aspects of Mycorrbizae, 217-221.

Turner NC : 2019. Imposing and maintaining soil water deficits in drought studies in pots. Plant and Soil, 439: 45-55. https://doi.org/10.1007/s11104-0183893-1

Van Parijs J, Broekaert WF, Goldstein IJ. and Peumans WJ : 1991. Hevein: an antifungal protein from rubber-tree (Hevea brasiliensis) latex. Planta. 183: 258 264.

https://doi.org/10.1007/BF00197797

Wu Q-S, Cao M-Q, Zou Y-N. and He X : 2014.

Direct and indirect effects of glomalin, mycorrhizal hyphae, and roots on aggregate stability in rhizosphere of trifoliate orange. Scientific Reports, 4: 5823 https://doi.org/10.1038/srep05823

Wu Q-S, Xia R-X. and Zou Y-N : 2008. Improved soil structure and citrus growth after inoculation with three arbuscular mycorrhizal fungi under drought stress. European Journal of Soil Biology, $\quad 44(1)$ : 122-128. https://doi.org/10.1016/j.ejsobi.2007.1 0.001

Xu Z, Wu Y, Xiao Z, Ban Y. and Belvett N : 2019. Positive effects of Funneliformis mosseae inoculation on reed seedlings under water and $\mathrm{TiO}_{2}$ nanoparticles stresses. World Journal of Microbiology and Biotechnology, $\quad 35(6)$ : 81. https://doi.org/10.1007/s11274-0192656-3 